\title{
Responsive feeding: the missing link in child malnutrition in Sri Lanka
}

\author{
Thilini Chanchala Agampodi ${ }^{1}$ \\ Sri Lanka Journal of Child Health, 2014; 43(1): 53-54
}

(Key words: Responsive feeding; child malnutrition; Sri Lanka)

Sri Lanka has made exemplary progress in maternal and child health during the past century. However, the stagnating child nutritional indicators during the past two decades have been a challenge to public health personnel in the country ${ }^{1}$. According to the Demographic and Health Survey (DHS) 2007, in infants 6 months of age, prevalence of stunting and wasting was $9.5 \%$ and $12.0 \%$ respectively. This prevalence doubles at the age of 12 months $(18.6 \%$ and $18.5 \%$ respectively). The trend of undernutrition gradually increases throughout the preschool period $(3-5 y r s)^{2}$.

The programmes implemented to combat childhood undernutrition in Sri Lanka are commendable. The national programmes for breastfeeding, complementary feeding, growth monitoring and promotion have helped to improve child nutrition to a certain level. The other aspects of child health are also well addressed through provision of universal coverage in immunization, safe water and sanitation. The strategies implemented in these programmes are based on prevailing global scientific evidence. However, with all these programmes, nutrition of children, especially after 6 months of age, remains a problem. Therefore, it is high time to think upon the missing links that impede optimal benefits of these programmes. One of the concepts related to infant and young child feeding, subject to comparatively less dialogue within the national infant feeding programme, is responsive feeding.

Responsive feeding is the fifth guideline in the Sri Lankan infant feeding guidelines ${ }^{3}$. It is embedded in responsive parenting and indicates how the caregiver should act in a responsive manner to address the child's hunger and satiety ${ }^{4}$. However, close observation during field services reveals that difficulty in making the child eat is one of the most common problems in both rural and urban communities in Sri Lanka resulting in suboptimal feeding patterns such as controlled feeding and indulgence. Meanwhile, a recent study done in

Lecturer, Department of Community Medicine, Faculty of Medicine and Allied Sciences, Rajarata University of Sri Lanka

(Received on 26 November 2013: Accepted after revision on 24 January 2014)
Anuradhapura district suggests that although the caregivers had adequate knowledge on complementary foods and their preparation, their knowledge and skills on responsive feeding was very poor $^{5}$. Even the caregivers who practised some aspects of responsive feeding did not have a clear idea about the scientific basis and the main constructs of the concept ${ }^{6}$.

In responsive feeding, the reciprocity between the child and the caregiver is conceptualized as a fourstep process ${ }^{4}$. These four steps include:

1. Pro-active preparation to have a pleasant and healthy feeding environment.

2. Identifying and encouraging child's signals of hunger and satiety.

3. Responding to the child promptly in an emotionally supportive, contingent and developmentally appropriate manner.

4. The child experiencing a predictable response to signals.

The pro-active preparation includes the caregiver arranging a pleasant, non-distractive environment where the child can be kept comfortable during feeding. This includes establishment of a routine for meal time according to the child's hunger cues. Proactive preparation helps the child to learn that meals should be taken in a specific place and at a routine meal time.

During the early periods of life, the child and the caregiver learn to recognize and interpret communication signals of one another. These signals could be verbal or nonverbal. Reciprocity developed through this process determines the emotional bonding which in turn develops trust, security, social and emotional development of the child ${ }^{7}$. In responsive feeding, it is important that the caregiver identifies the child's signals of hunger and satiety which could be different from one child to another. Spending time with the child will help the caregiver identify these signals.

When the signals are identified, the caregiver should act promptly, in an emotionally supportive manner. The selected foods and the way of feeding should be developmentally appropriate. The caregiver should encourage development of child's skills such as self- 
feeding. As a result of this process the child builds up trust with the caregiver.

Development of skills of caregivers to practise responsive feeding will have many benefits. Responsive feeding can influence dietary intake and optimize eating behaviours of children ${ }^{8}$. This will help caregivers to get rid of common non-responsive feeding behaviours such as controlled or pressurized feeding, indulgence and ignoring of the child's hunger. Its implication on child's psychosocial and autonomy development is immense ${ }^{4}$.

The Sri Lankan infant feeding programme has been very strong in culturally adapting and incorporating many evidence based strategies at local setting. As the literacy and health practices of women in Sri Lanka are high, incorporating caregiver skills development in feeding practices would fill a serious gap in service provision.

\section{References}

1. Family Health Bureau,Sri Lanka. Annual Family Health Report 2008/2009.

2. Department of Census and Statistics, Sri Lanka Demographic and Health Survey 2006/7 Preliminary Report. 2007. Department of Census and Statistics in collaboration with Ministry of Healthcare and Nutrition: Colombo. p. 13-14.

3. Ministry of Healthcare and Nutrition, Infant and young child feeding guidelines. Family Health Bureau Sri Lanka 2007
4. Black MM and Aboud FE. Responsive feeding is embedded in a theoretical framework of responsive parenting. Journal of Nutrition 2011; 141(3): 490-4.

http://dx.doi.org/10.3945/jn.110.129973

5. Agampodi TC, Chathurani KU, Agampodi SB. Infant feeding behaviours in NuwaragamPalatha-Central Medical Officer of Health area; a qualitative study. Anuradhapura Medical Journal; 6 (1), 33.

6. Senanayake MP, Rodrigo R. Extreme food refusal resulting in pellagra in a toddler living in the "maize belt" of Sri Lanka. Sri Lanka Journal of Child Health 2013; 41(3): 166-7.

7. Kochanska G, Woodard J, Kim S, Koenig JL,Yoon JE, Barry RA. Positive socialization mechanisms in secure and insecure parent child dyads:two longitudinal studies. Journal of Child Psychology \& Psychiatry 2010; 51:998-1009 http://dx.doi.org/10.1111/j.14697610.2010.0223 8.x

8. Bentley ME, Wasser HM, Creed-Kanashiro HM, Responsive feeding and child undernutrition in low- and middle-income countries. Journal of Nutrition 2011. 141(3): 502-7

http://dx.doi.org/10.3945/jn.110.130005 